\title{
Acceptance and Commitment Training in Applied Behavior Analysis: Where Have You Been All My Life?
}

\author{
Amanda D. Kelly ${ }^{1}$ (D) Michelle E. Kelly ${ }^{2}$ \\ Accepted: 31 March 2021 / Published online: 29 July 2021 \\ (C) Association for Behavior Analysis International 2021
}

\begin{abstract}
Examining behavior within the context of applied behavior analysis (ABA) from the perspective of acceptance and commitment training (ACTr), while understanding the role of relational framing and the transformation of stimulus function, can better equip behavior analysts to effectively address complex behavior that may be influenced by covert verbal behavior. This approach may lead to a more comprehensive analysis of behavior and result in more effective interventions for socially significant change. The aim of this article is to provide behavior analysts with information and guidance on using relational frame theory (RFT) and ACTr in behavior-analytic services. The article first provides a rationale for considering thoughts as behavior and outlines important components of RFT. Subsequently, the benefits of employing ACTr in ABA are highlighted, including brief descriptions and examples of the use of ACTr within ABA practice. The article highlights the importance of expanding the consideration of maintaining variables when attempting to address maladaptive covert verbal behavior and ultimately aims to encourage a greater number of behavior analysts to adopt RFT and ACTr practices in applied settings.
\end{abstract}

Keywords Acceptance and commitment training (ACTr) · Applied behavior analysis (ABA) · Relational frame theory (RFT) . Verbal behavior

Acceptance and commitment training (ACTr) refers to the implementation of acceptance and commitment therapy (ACT) outside of psychotherapy settings (S. C. Hayes et al., 1999) and has been referred to in research literature since the early 2000s (e.g., Hayes et al., 2004a, b; Moran, 2011). ACTr has become increasingly popular in applied behavior analysis (ABA) in recent times, with researchers actively exploring its scope of practice (Enoch \& Nicholson, 2020; Sandoz et al., 2021; J. Tarbox, Szabo, \& Aclan, 2020b) and usability as a behavior-analytic method (Dixon et al., 2020). ACTr is also being examined as an avenue for the field of ABA to address broader social issues. For example, research articles prompted by the novel coronavirus (COVID-19) pandemic, such as the

Amanda D. Kelly

Akelly@ fireflyautism.org

Michelle E. Kelly

Michelle.Kelly@ncirl.ie

Firefly Autism, 2001 Hoyt Street, Lakewood, CO, USA

2 National College of Ireland, Mayor Street Lower, IFSC, Dublin, Ireland
Behavior Analysis in Practice emergency series (e.g., Coyne et al., 2020; Szabo et al., 2020; C. M. Tarbox, Silverman, et al., 2020a, have provided guidance, information, strategies, tools, and resources to those in the behavior-analytic community to navigate challenges presented by COVID-19. Seven of the 24 articles in the series included components of ACT. During the Black Lives Matter Movement in 2020, many behaviour analysts in public groups or on podcasts (e.g. Harrison, 2020) called on the field of ABA to address systemic racism and racism related behaviors within our workplaces and communities. ACTr has the potential to reduce racial bias (Matsuda et al., 2020), and related research on relational frame theory (RFT) provides a perspective on how behaviors as complex as relational biases may occur (e.g., D. BarnesHolmes et al., 2010; de Carvalho \& de Rose, 2014).

ACTr therefore has the potential to address issues of social significance that affect individuals worldwide, and enrich the practical capabilities of behavior analysts. As such, it is important that ABA practitioners are aware of when and how ACTr is relevant (also see Sandoz et al., 2021). The aim of this article is to outline how the implementation of ACTr in ABA settings may increase treatment effectiveness across a wide range of individuals and levels of functioning. A behavior-analytic 
understanding of both direct and indirect variables (e.g., covert verbal behavior, thoughts, or feelings) in context can provide behavior analysts with the ability to analyze a wide range of variables that maintain problem behavior. This type of analysis may be helpful in identifying relevant contingencies and therefore lead to expanded or more effective treatment options (e.g., in cases where direct contingency management alone has been unsuccessful). First, the rationale for considering private events such as thoughts and feelings in behavior analysis will be presented, followed by an outline of the relevance of RFT. Subsequently, the benefits of employing an ACTr analytic approach in ABA practice will be highlighted, including a description of the use of ACTr within an ABA context. Before proceeding, we would like to note that this is an exciting time for the field of ABA with many developments and important perspectives constantly being published on ACTr and RFT. That said, this paper does not intend to provide a comprehensive account of all recent literature on these topics, instead we wish to present (hopefully) accessible information to encourage practising behavior analysts, that may shy away from these topics, to begin to consider the use or applicability of ACTr and RFT in their work.

\section{A Rationale for Considering Thoughts as Behavior}

A fundamental aim of ABA is to analyze all variables that influence the probability of behavior (Biglan \& Kass, 1977; Skinner, 1969). As such, behavior analysts must examine specific behaviors, as well as other influential variables including the organism, the environment, and motivation, as a change in any one of these variables can have an effect on the behavior being analyzed (Szabo \& Tarbox, 2015). Imagine instances where a socially significant maladaptive behavior is attributed to anxiety, stress, depression, fear, and so on. The issue is that "having anxious thoughts" may be difficult to analyze in a way that establishes a relationship between these thoughts and the maladaptive behavior (Friman et al., 1998). If anxious thoughts were viewed as behaviors, however, then both public and private behaviors could be influenced by manipulating the environment or context within which the behavior occurs (Hughes \& Barnes-Holmes, 2016). The concept of thoughts as behavior and the ability of thoughts to guide overt behavior itself make covert verbal behavior (i.e., thoughts) just as legitimate a target as an overt behavior alone.

In typical ABA settings, contingency management is direct in that changes are applied to the direct environment. The behavior analyst identifies a certain behavior, conducts a functional assessment to formulate hypotheses regarding function, and considers context, motivating operations (which typically refer to states of deprivation or satiation), discriminative stimuli, and consequences. Contingency management occurs via the organization of contingencies such that the behavior is modified appropriately, allowing the behavior analyst to teach adaptive alternative responses. Direct contingency management is an essential part of ABA practice; however, there may be limits when considering the treatment of behaviors that are not under the control of direct environmental contingencies (Dixon et al., 2020) — that is, the difference between behavior under the control of a physical or external aversive stimulus (direct) and behavior under the control of a thought/ feeling (indirect). If a behavior analyst has used direct contingency management for a long time with limited or no success, considering private events that can be thought of as indirectacting contingencies may aid a more thorough analysis of potential maintaining variables.

Skinner (1945) supported the behavioral analysis of private events, but it took several years before RFT and ACT literature provided further clarity on how the analysis of private events could be achieved. Nowadays, many behavior analysts would agree that private events are a legitimate target for ABA, but many still shy away from working with private events despite the utility of considering thoughts as behavior. Adopting an RFT analysis of verbal behavior and using ACTr provide a pathway for behavior analysts to confidently consider thoughts as behavior, and allow for a behavioral analysis and treatment of behavior associated with or affected by such. There are existing barriers, however; for example, Dixon et al. (2020) highlighted the potential resistance of the behavioral community to broaden conceptualizations of language beyond traditional Skinnerian approaches. Behavior analysts may also feel that addressing these types of behaviors is outside of their scope of competence or practice. Although recent articles have attempted to address many of these issues (e.g., Dixon et al., 2020; Sandoz et al., 2021; Tarbox, et al., 2020b), behavior analysts may still struggle with the practical applicability of RFT and ACTr in day-today practice. For many, the time needed to learn about RFT and ACTr is a prohibiting factor. That being said, if our field is to advance such that meaningful behavioral change can be afforded to a broader variety of clients, it is important for behavior analysts to learn about these approaches. Before considering ACTr in ABA, basic components of an RFT analysis of verbal behavior will be outlined.

\section{RFT and Private Events}

The relevance of RFT to ACT is well established in the literature (Y. Barnes-Holmes et al., 2018; Blackledge \& BarnesHolmes, 2009; Hayes et al., 2004b; Hayes et al., 2006), where RFT is explained as having provided the conceptual foundations for ACT (Zettle, 2005) and has made important contributions to an ACT perspective of psychopathology (Y. Barnes-Holmes, Barnes-Holmes, \& Smeets, 2004) and 
intervention (Foody et al., 2013; Guinther \& Dougher, 2015; Hayes et al., 2004b). For ACTr, understanding important features of RFT should be helpful for the functional assessment of indirect-acting (and indeed direct-acting) contingencies and the development of well-informed treatment goals. These features of RFT include derived and arbitrarily applicable relational responding, mutual entailment, combinatorial entailment, and the transformation of stimulus function (ToSF).

Relational responding, first of all, occurs when people verbally (covertly or overtly) relate stimuli to one another. Examples of relational responses include sameness, opposition or difference, more or less than, bigger or smaller than, different perspectives, hierarchical relationships such as familial or societal roles, causal or contingency relationships, and so on. During language development, humans become well practiced at understanding relationships between stimuli and can derive relationships between nonarbitrary and arbitrary stimuli (Y. Barnes-Holmes et al., 2018). A relational response is derived when it emerges without any direct training or reinforcement (Y. Barnes-Holmes, Barnes-Holmes, \& Smeets, 2004). A relational response is nonarbitrary when it is based on the physical properties of the stimuli (e.g., "Sarah is taller than Mary"), and is arbitrary when it is based on contextual cues (i.e., words/ phrases with socially constructed meaning) and not on any physical properties (e.g., "Mary is 'the bigger person' for walking away from an argument with Sarah"; Kelly, 2020). Derived relational responding, therefore, refers to the derivation of any relational response, whereas arbitrarily applicable relational responding (AARRing) refers specifically to relational responses that are arbitrary (S. C. Hayes et al., 2001). Further examples are provided for clarity.

An example of a derived relational response is as follows: If you were told that "Sarah (A) is taller than Mary (B)," then you could derive one additional relation without explicitly being told: that Mary (B) is shorter than Sarah (A). This is termed mutual entailment (if $\mathrm{A}>\mathrm{B}$, then $\mathrm{B}<\mathrm{A}$ ) and refers to the bidirectional nature of relationships between stimuli. If you were later told that Mary (B) is taller than Jane (C), then you could derive three additional relations: that Jane is shorter than Mary (if B $>C$, then $C<B$ ), that Sarah (A) is taller than Jane (C), and that Jane (C) is shorter than Sarah (A). This is termed combinatorial entailment (if $\mathrm{A}>\mathrm{B}>\mathrm{C}$, then $\mathrm{A}>\mathrm{C}$ and $\mathrm{C}<\mathrm{A})$. The ToSF occurs when the function or "effect" of a stimulus is transformed by virtue of its relationship to another stimulus; or more specifically, when two stimuli are related, the functions of each stimulus can change according to how they are related. Continuing with the prior example, imagine that you play basketball with Mary and she is one of the best players on the team. Your coach states, "The taller, the better," and attributes Mary's success to her height. Then imagine a new player, Sarah, joins the team, and she is taller than Mary. You do not know Sarah and have never played with her before, but during the next game, you predominantly throw the ball to her and are less inclined to throw it to Mary. In this example, Mary's success at basketball is attributed to her height, so when she enters into a frame of comparison with Sarah, who is even taller, Sarah is assumed to be the better player through the ToSF.

The previous example is relatively simplistic as it is mostly based on nonarbitrary relationships between stimuli (physical height), but as mentioned previously, humans are also proficient at understanding more complex, arbitrary relationships. Understanding arbitrary relational responses and the ToSF is arguably most important for comprehending how overt behavior may be related to covert verbal behavior in applied settings. At this point, therefore, we will provide examples of AARRing and the ToSF that may impact behavior in an applied setting.

Consider an example of a client in high school who attends a party, and peers tell them they are "cool" for drinking alcohol. Let's say the client establishes the rule that drinking makes you cool. The client is later told that "drugs are better than alcohol." Drugs enter a "better than" frame of comparison with alcohol, and by virtue of this stated relationship, the client infers that drugs make you even cooler. The client has used AARRing to arrive at this conclusion, as the relationships between drugs, alcohol, and "being cool" are determined by words/phrases with socially constructed meaning and not by any tangible physical properties. The client, who has a desire to be considered cool by their peers, starts using drugs, the appetitive function of which lies in the ToSF (Dymond \& Rehfeldt, 2000). That is, if the function of drinking alcohol is to be cool, and drugs are comparable to alcohol, then the function of alcohol (being cool) can transfer, via the arbitrary contextual cue "better than," to drugs (being even cooler).

The same can be said for aversive functions. Consider a client who has a fear of dogs because they were bitten by a terrier when they were younger. Being bitten by the terrier was very painful and caused a huge amount of distress for the client, and they became terrified of that specific terrier as a result. The fear of the attacking terrier then generalized to a fear of all terriers and all dogs, as "that terrier" entered into a frame of sameness/coordination with "all terriers" and into a frame of hierarchy with "dogs." So, if the person is afraid of that terrier, and that terrier is the same as all terriers, and terriers are all dogs, the fear of one terrier may generalize to a fear of all dogs as the function of one stimulus (i.e., fear of a terrier) transfers to the other related stimuli via the ToSF. Similarly, the memory of the pain and the physiological and emotional distress of being bitten by a dog can enter into a frame of coordination with being in the presence of actual dogs and also speaking/thinking about dogs. Subsequently, via the ToSF, the function of the stressful event (the dog bite) can transfer to thinking about dogs, and these thoughts may then evoke emotional distress and physiological stress responses, such as an increased heart rate. Now imagine that 
the client overhears a conversation where their aunt says that they regret getting a dog at the same time as having a new baby, as the dog is "like a baby"; crying and in need of constant attention. By virtue of the frame of coordination, and as explained previously, the new baby may now acquire the aversive functions of dogs. The client already avoids any family members who have dogs and now refuses to attend family gatherings if the baby will be there. This behavior is now being maintained by nonsocial negative reinforcementspecifically the avoidance of stimuli that evoke feelings of fear or discomfort. Again, understanding the function of this verbal stimulus ("The new baby will be there") lies in the ToSF, as no explicit history of direct reinforcement exists for the behavior that the verbal stimulus has occasioned.

Ultimately, when humans make relational responses between stimuli, this can result in the ToSF for all of the stimuli involved (see Blackledge, 2003, for a more detailed explanation). The ToSF, and RFT as a whole, helps us understand how overt or covert verbal behavior is essentially a vehicle through which emotions, psychological suffering, and even physiological sensations can travel (Pennie \& Barnes-Holmes, 2019; Pennie \& Kelly, 2018). Understanding derived relational responding, AARRing, and the ToSF could therefore help a behavior analyst in an applied setting to further comprehend why a behavior might be occurring and the role that covert verbal behavior may play. For a comprehensive overview of recent advances in RFT that may further inform an analysis of verbal behavior, see BarnesHolmes et al., (2020).

\section{ACTr in ABA: Functional Assessment to Function-Based Treatment}

The previous section illustrated how covert verbal behavior can have real effects on overt, observable, and measurable behaviors. In ABA, the functions of behavior refer to specific variables that occasion and maintain behavior- essentially the purpose of behavior. Functions of behaviors can be determined by analyzing antecedents and consequences within a person's environment (Cooper et al., 2007). Decades of research have led to widespread acceptance of four main functions of behavior: social-positive reinforcement such as access to attention and tangibles, social-negative reinforcement such as escape/avoidance of demands, non-social-positive reinforcement such as automatic or sensory stimulation, and non-social-negative reinforcement such as pain attenuation (e.g., Iwata et al., 1994). However, when you consider the breadth of types of relational responses that can be derived, and how quickly functions of one stimulus can transfer to another just by virtue of that relationship, it becomes clear that broadening the conceptualization of functions of behavior to go beyond these four main direct-acting functions should be beneficial in addressing more complex client behaviors. With a broader analysis that considers the impact of AARRing and the ToSF, it becomes apparent that private events such as thoughts/feelings can function to occasion or maintain observable, measurable behaviors. In the previous example of the client who avoids family dinners, we demonstrated how non-social-negative reinforcement was relevant to indirectacting contingencies of thoughts and feelings. ACTr can provide behavior analysts with the tools required to analyze and intervene on behavior being influenced by private events.

Creating or enhancing flexible behavioral and relational repertoires may be an important goal of applying ACTr in ABA. Behavioral flexibility refers to a person's ability to behave in ways that may or may not cohere with their preferred or more common patterns of behavior. Consider the example of the client in the previous section again; flexible behavior would be observed if they still attended the family dinner, even in the presence of the difficult thoughts/feelings that may be occasioned by the baby's presence. Relational flexibility refers to a person's ability to switch readily between opposing patterns of AARRing (D. Barnes-Holmes et al., 2017; Kelly, 2020) and would be observed if the client were able to consider the differences between babies and dogs and not just the similarities (i.e., in the context of babies and dogs, being able to switch between relational responses of sameness and opposition). ACTr-based interventions may be approached using the ACT core processes of acceptance versus experiential avoidance, flexible versus rigid perspective taking (known as self-as-context vs. self-as-content), defusion versus fusion, present-moment awareness versus rigid orientation to the past or future, clear values versus unclear values, and committed action versus lack of committed action (see $\mathrm{S}$. C. Hayes et al., 2006, for outlines of each). Although we understand that the use of the core processes within ACT has been a topic of debate (Barnes-Holmes et al., 2016; Barnes-Holmes et al., 2018; Sandoz et al., 2021), and they are not behavior-analytic terms, they may offer a useful conceptual framework for behavior analysts in applied settings to begin examining covert verbal behavior (thoughts/ feelings) as variables that may affect or maintain problem behavior.

The following section will consider how these concepts may be helpful as a starting point for an analysis of problem behavior maintained by covert verbal behavior. This will include brief examples of how broader analyses may lead to more effective treatment with verbally able clients, the purpose of which is to highlight the importance of expanding the consideration of variables that influence client behavior. See Hoffmann et al. (2016), Little et al. (2020), and Tarbox, Szabo, and Aclan (2020b) for further descriptions of the use of the six ACT processes in ACTr, and possible $\mathrm{ABA}$ treatment options relative to each. 


\section{Lack of Values Versus Values}

Values may be defined behaviorally as "rules that function as verbal motivating operations that increase or decrease the effectiveness of stimuli as reinforcers or punishers, thereby supporting overt behaviors that produce those stimuli" (Tarbox, Szabo, \& Aclan, 2020b, p. 3). The value itself often presents as an abstract verbally constructed outcome that the person is working or would like to work toward (e.g., being a good friend, being a good brother/sister). Values also include augmenting, in that the reinforcing nature of certain behaviors is determined by values-driven verbal rules (e.g., a rule "Good friends reach out to and respond to friends" can evoke behaviors such as responding to a peer initiation in the service of the goal/value to "be a good friend"). By incorporating values into intervention plans, behavior analysts may have more options to promote client engagement in adaptive behaviors. The behavior itself might be reinforcing due to the connection to the "outcome," versus relying solely on external reinforcers or typical motivating operations to reinforce or increase the likelihood of engagement in adaptive behaviors.

\section{Experiential Avoidance Versus Acceptance}

Experiential avoidance occurs when an individual engages in behaviors to avoid or escape aversive stimuli in the form of thoughts/feelings (vs. engaging in behaviors to avoid or escape an actual thing, task, or person, which would simply be considered escape/avoidance in ABA). The adaptive alternative is accepting negative thoughts/feelings and starting or continuing to engage in adaptive behaviors necessary to reach important goals. This is not a new concept; language-able humans engaging in behaviors to eliminate or reduce the occurrence of aversive private events have been a source of analysis for years (e.g., Friman et al., 1998). Avoiding discussions, avoiding or refusing to engage with an activity or person due to the physical or emotional feelings that may arise, or using substances to reduce the occurrence of thoughts or memories are behavioral outcomes that correspond with a functional interpretation of experiential avoidance (as opposed to direct contingency avoidance).

Imagine a scenario where a behavior analyst is attempting to treat client aggression, and has observed that the behavior increases either during or right before their parents put on the morning or evening news; however, it is inconsistent. Based on all assessments completed, the behavior analyst determines that the function of the behavior is escape/avoidance of the news. Now, imagine that the client has stated that newsreaders sitting at a desk "look like" teachers in school. Assessment previously identified that the client was bullied at school. Through derived relational responding, the news reader reminds the client of teachers at school, which reminds the client of bullies at school who made fun of them, and that makes the client remember feelings of inadequacy, anger, and sadness that they experienced at school due to bullying. The behavior analyst may create an intervention plan based on the presumed function of escape/avoidance from news clips; however, the intervention may only be minimally successful. The stimuli that have entered into a frame of coordination with school (people sitting at desks, bullies, the memory of being bullied, the feelings associated with being bullied) will never leave that frame. In fact, that frame is likely to continue to grow as the client derives more relationships between other stimuli and those aversive memories of school. If the analyst had exhausted all direct contingency avenues to no avail, they may consider functional relations that correspond with behaviors that might be identified during experiential avoidance. Namely, the behavior of the client may function to reduce negative thoughts and feelings associated with school. Should this be included alongside our known and beloved direct contingency management, a treatment package might look like teaching the client acceptance of aversive thoughts and progress toward accepting or tolerating the thoughts and feelings associated with thinking about school. This would all be taught while engaging the client in adaptive skills that help the client to access things that are important to them- that is, engaging in behavior consistent with the client's goals. In the previous example, an understanding of RFT and the ToSF may better equip behavior analysts to make a more thorough analysis with increased intervention options.

\section{Fusion Versus Defusion}

Fusion refers to thoughts as literal truths that should be acted on, whereas defusion refers to the understanding that thoughts are just thoughts, which come and go.

Fusion can be conceptualized behaviorally as behavior under the control of verbal rules, whereby a person's behavior is so controlled by verbal rules that it becomes problematic. It can also encompass attending to thoughts rigidly and engaging in behaviors based on those thoughts even if the behavior is maladaptive or problematic. The alternative is defusion, which essentially refers to flexibly "responding" to verbal rules in ways that are adaptive, attending or responding to thoughts as just thoughts, and making a decision about the usefulness or otherwise of thoughts. The client can then make a conscious decision to engage in behaviors based on useful thoughts or just let other thoughts pass.

Consider a client who repeatedly thinks (and may say out loud) that they will never be successful because they have autism. Imagine that the client believes that this thought is a truth, not merely a thought that they have. The client has a difficult time getting a job and being financially independent, which they have identified as the most important thing to them. The behavior analyst sets up contingencies around job seeking. The client engages in some job-seeking behaviors but 
time and again displays a lack of motivation to engage consistently in those behaviors. The client states openly, "The system is rigged, and I won't get it anyway because I have autism." The behavior analyst is out of ideas because all the antecedent management strategies and consequences should be working. Expanding conceptualization to include this type of rule-governed behavior as a maintaining variable of the problem behavior would have the behavior analyst include replacement behaviors that would promote defusion, such as noticing thoughts as just thoughts, not literal truths. This may progress to the client being able to pause and state, "Ah! I'm having the thought that the system is rigged so there's no point. But I know it is just a thought, so I will try anyway."

\section{Self-as-Content Versus Self-as-Context}

Deictic framing is a type of relational framing in which relations are specified in terms of the speaker. Support has been shown for deictic framing as an operant account of perspective taking (McHugh et al., 2004). This type of relational framing is closely tied to the concept of self-as-context, commonly known in ACT literature as the observing self. The observing self is a state by which a person understands that the self is a locus from which they can observe their thoughts and feelings, different states, and different aspects of "self." Behaviorally, self-as-context can be conceptualized as flexible perspective taking. The alternative, self-as-content, refers to a person defining themselves by certain content-for example, "I'm a mother; that's all I know how to be. Without that, I would be nothing." Behaviorally, self-as-content can be conceptualized as inflexible or rigid perspective taking. Clients who struggle with flexible perspective taking in relation to the self may see themselves in a very rigid way (e.g., "I'm the smart one!"). Similar to rule governance described in fusion, this also includes a rule that a person has verbally constructed about themselves. As such, there is some overlap between fusion and self-as-content; however, self-as-content is a rule specific to the speaker themselves. Note that in the previous example, the client does not see themselves as only being an "autistic person" (self-as-content), but rather the client sees that the world is working against people with autism, so it is stated like a rule (fusion).

Consider a client who is refusing to go to college or engage with assigned texts. Based on the direct and indirect assessments completed, the behavior analyst has hypothesized that the function of the behavior is escape/avoidance of college work. However, the behavior analyst has also identified that attending college is something that is very important to the client - they say so daily. Access to a highly preferred video game is kept contingent on engaging with assigned texts for $20 \mathrm{~min}$ three times per week. Despite antecedent manipulations and consequences that the analyst believes should work based on the identified functions, the client not only skips college but also rarely meets any targets to engage with assigned texts. The behavior analyst needs to change strategy and starts to pay attention to verbal behavior and the functions related to indirect-acting contingencies. The client repeatedly says that they are a "math person" and that they are "the smart one." Further investigation uncovers that this sense of self has been rigid for many years. The behavior analyst hypothesizes that the client is behaving in such a way as to avoid undermining their own rule about themselves. The client does not want to engage with the assigned texts or go to college because it is challenging. They feel that if they fail, their whole identity as "the smart one" may be in jeopardy. The client is essentially identifying themselves as the content of their thoughts, as opposed to a person who has thoughts. When this behavior is related to the ACT core processes, individuals might orient to self-as-content or rigid perspective taking. The behavior analyst might then look to the flexible alternative - self-as-context - to consider broader treatment options. Treatment may consist of regular, direct contingency management and approaches considered indirect acting, such carefully planned verbal statements or verbal discriminative stimuli that include examples of how "you can still be the smart one and make mistakes" and how the many parts of the "self" shift from time to time depending on the context, but the whole self is always present.

\section{Lack of Present-Moment Awareness Versus Present- Moment Awareness}

Present-moment awareness refers to the conscious ability to be fully present in the moment in order to more meaningfully connect with life as it happens. The alternative refers to difficulty remaining present and thus missing things that are happening in the present moment - essentially living inside one's head versus in the world. Behaviorally, lack of presentmoment awareness can be conceptualized as a client orienting or attending to stimuli in the form of thoughts, feelings, or memories about the past or future. The adaptive alternative is being able to flexibly orient to current relevant stimuli as needed. Thus, the client can both have a conscious awareness of when they are oriented to past or future stimuli and can also flexibly shift to present-moment awareness or orient to current stimuli. Behavior analysts may observe problematic attending or orientation to the past or future in their clients as perseverative or repetitive. Repeated or persistent thoughts about the past or future can lead to overt behavior such as repetitive statements referring to the thoughts that may well interfere with adaptive client functioning, such as meaningful social exchanges with family or peers. Consider a scenario where the behavior analyst has determined that the function of repetitive statements about the past and future is positive reinforcement in the form of attention from peers or family. The behavior analyst teaches replacement behaviors in the form of 
gaining attention in other ways, along with an extinction procedure, with limited success. Expanding consideration to verbal behavior processes may determine that perseverative thoughts about the past or future are creating barriers to orienting to current stimuli. The behavior analyst might add the use of verbal statements to teach the client flexible responding to the current treatment package. This may include prompting the client to become aware of current thoughts, such as "I'm thinking about what is going to happen when I have to go back to school in person again," and adapting to present-moment awareness: "But right now I'm going to listen to and talk with my sister." Present-moment awareness can also be tied to values in that orientation to relevant stimuli in the present might make an individual more likely to be able to engage in behaviors that bring them closer to their values (e.g., being a good friend).

\section{Lack of Committed Action Versus Committed Action}

Committed action refers to engagement in behaviors that move the person toward their values, which involves an awareness of the values themselves. Lack of committed action is the lack of understanding of what behaviors might be relevant and what values the person is moving toward and the lack of engagement in those behaviors. Behaviorally speaking, the committed action itself is easily identifiable once the behaviors and values have been outlined. Clients may be able to identify their values and what behaviors they need to engage in, but they may still struggle with actually following through with the needed behavior.

At times, necessary parts of treatment include clients (the client themselves or a parent) committing to doing things outside of session times. The behavior analyst has little control over whether this will actually happen, so they must rely on the motivation of the client or parent. The behavior analyst can create a plan that is low in terms of demand, very clear, and easy to follow, and the client will say that they will engage in the requested behavior. However, the person may not actually engage in the behavior when the time comes. Behavior analysts who have significant barriers to parent training or clients following through with requested behaviors may be inclined to discharge due to a lack of ability to further progress. If the behavior analyst were to consider linking committed actions to the client's or parent's own verbally constructed values (e.g., to be a good parent), they may be more likely to be successful when requesting those actions or behaviors of clients.

When we broaden our consideration of behavioral contingencies to include covert verbal behavior as variables that influence or maintain behavior, we have the potential to be more effective at reducing problematic behaviors and increasing skill repertoires that lead to flexible and adaptive responding by the client.

\section{RFT and ACTr Resources}

$\mathrm{ACTr}$ and RFT research has produced a vast amount of resources that can assist behavior analysts with client treatment. Using training in derived relational responding has long been identified as important to significantly improve teaching methods used in educational settings (Y. Barnes-Holmes, Barnes-Holmes, \& McHugh, 2004a). Many articles have been published that identify the positive outcomes associated with training nonarbitrary and arbitrary relational responses to advance the verbal repertoires of autistic individuals (e.g., Murphy et al., 2005; Rehfeldt et al., 2007); literature outlines the practical applications of RFT for those with whom the ABA community typically works (Rehfeldt \& Barnes-Holmes, 2009) and provide detailed analyses of each core concept of RFT (Barnes-Holmes et al., 2020; Fryling et al., 2020). Curriculum-based intervention and assessment materials based on RFT and ACTr have been published for use by behavior analysts, including the Promoting the Emergence of Advanced Knowledge (PEAK) assessment and training protocol (McKeel et al., 2015); the Accept, Identify, Move (AIM) curriculum (Dixon \& Paliliunas, 2018); the Thriving Adolescent/ Discoverer Noticer Advisor-Values (DNA-V; L. L. Hayes \& Ciarrochi, 2015); and more recently, Connect, which is an online training program promoting children's psychological flexibility and well-being based on the DNA-V but for children ages 4-11 years (see https://www.connect-pshe.org). Researchers have also published parent-training protocols that use ACTr (e.g., Gould et al., 2018). Although data are not available on how often each is used, it is important for behavior analysts to be aware of the RFT- and ACTr-based resources available to them. If a behavior analyst can develop an understanding of language development, even from a basic RFT perspective, they are arguably much better equipped to develop hypotheses about functions of behavior that they have been unsuccessful at addressing. ACTr can then provide a way in which to pinpoint an appropriate intervention based on the hypothesized function of behavior.

Once target behaviors have been adequately assessed via thorough functional assessment (see Sandoz et al., 2021 for a helpful outline of direct ongoing behavior analytic functional assessment in ACTr), and there is a hypothesis on maintaining variables and the direction of intervention, programming for treatment follows. A potential barrier for behavior analysts may be programming for ACTr-type goals in an ABA-consistent format or within widely used practice management systems (e.g., CentralReach, Catalyst). Essentially, behavior analysts may struggle to write goals that are congruent with typical ABA programming. Table 1 provides practical examples of how goals might be adapted to a format familiar to behavior analysts, that can easily be entered into $\mathrm{ABA}$ practice management systems. 
Table 1 Sample programming for ACTr-type goals

\begin{tabular}{|c|c|}
\hline Goal Step & Description \\
\hline \multicolumn{2}{|c|}{ Present Moment Awareness } \\
\hline Antecedent: & $\begin{array}{l}\text { Naturally occurring during the ABA session, capture opportuinities for noticing of sights, sounds, smells, touch and internal thoughts } \\
\text { or physical feelings. }\end{array}$ \\
\hline $\begin{array}{l}\text { Sample } \\
\text { Prompt: }\end{array}$ & $\begin{array}{l}\text { Give full vocal prompt when appropriate to prompt noticing (e.g., "I see you are touching the } \\
\text { paper, what does that feel like"/ "what do you feel on your skin?", "what do you see/hear?" } \\
\text { "how do you feel on the inside", etc. }\end{array}$ \\
\hline Behavior: & $\begin{array}{l}\text { Client will pause (defined as a pause in movement and vocal responding for } 1 \text { second or more) } \\
\text { and vocally tact } 5 \text { or more things that he notices either inside himself (thought, feeling), senses } \\
\text { (physical feelings on his skin, taste, smell, sounds, etc) or around him (what others are doing, etc.) } \\
\text { Mark as } 1 \text { trial for pause, and } 1 \text { trial for each sense/thought/physical feeling independently tacted. }\end{array}$ \\
\hline Consequences: & $\begin{array}{l}\text { Correct: FR1 Descriptive praise for each sense tacted at the current prompt level (e.g., I love how } \\
\text { you noticed that the paper feels dry and smooth!") } \\
\text { Incorrect: (e.g.Client fails to respond; Client repeats therapists own self-evaluation; Client engages in maladaptive behavior or } \\
\text { requires additional prompting beyond initial model). If incorrect, utilize full vocal prompt - e.g., "how does the paper feel in your } \\
\text { hand? Is it soft, hard, smooth? What is } \\
\text { your brain saying right now? I can see the playroom, what can you see?" etc. and mark as } \\
\text { incorrect/prompted trial. } \\
\text { If client tacts less than } 5 \text { sensations/thoughts/feelings provide vocal prompt and mark as } \\
\text { incorrect/prompted trial. }\end{array}$ \\
\hline \multicolumn{2}{|c|}{ Defusion (Noticing Thoughts) } \\
\hline Antecedent & $\begin{array}{l}\text { Naturally occurring during the session, capture opportunity and present Vocal Sd: "Let's } \\
\text { notice some of our thoughts right now. Tell me something that your mind is telling you." }\end{array}$ \\
\hline $\begin{array}{l}\text { Sample } \\
\text { Prompt: }\end{array}$ & $\begin{array}{l}\text { Current prompt: Full vocal prompt for saying "my mind is telling me" and prompt to } \\
\text { say why his mind might be telling him the thought. (Client should independently } \\
\text { identify what the thought is). }\end{array}$ \\
\hline Behavior: & $\begin{array}{l}\text { Client uses verbiage (e.g., My mind is telling me, I noticed that I had the thought, I noticed, } \\
\text { my mind said, etc.) to say that he noticed a thought, }(1 \text { trial }) \text { what that thought is }(1 \text { trial }) \\
\text { and why his mind might tell him that thought }(1 \text { trial). Score } 3 \text { total opportunities per presentation. }\end{array}$ \\
\hline Consequence: & $\begin{array}{l}\text { Correct: FR1 Descriptive praise - e.g. "I love how you told me your mind was telling you } \\
\text { this is a bad idea!" } \\
\text { Incorrect: (e.g. Client fails to respond; Client repeats therapists own self-evaluation; Client engages } \\
\text { maladaptive behavior or requires additional prompting beyond initial model). If incorrect, model sample thoughts that the therapist } \\
\text { is having, reiterate Sd and give full vocal prompting } \\
\text { for all steps, have the client repeat. Mark as incorrect/prompted trial. }\end{array}$ \\
\hline \multicolumn{2}{|c|}{ Defusion (Defusing Thoughts) } \\
\hline Antecedent & $\begin{array}{l}\text { *Client has already identified "funny voice" for thoughts (e.g., Inside Out Movie character, Sadness) for recurring negative thoughts* } \\
\text { Present vocal Sd: "what does your mind sound like when it is telling you things that make you feel sad"? }\end{array}$ \\
\hline Behavior & $\begin{array}{l}\text { The client will use their selected "funny voice" to name their thoughts. (e.g., In Inside Out character voice: "I'll never be good enough, } \\
\text { COVID is never going away, I'll never have any friends") }\end{array}$ \\
\hline $\begin{array}{l}\text { Sample } \\
\text { Prompt }\end{array}$ & Therapists will pick a funny/silly voice and model using it to name some of their own negative thoughts. \\
\hline Consequence & $\begin{array}{l}\text { Correct: FR1 Descriptive praise - e.g. "I love how you did that, it sounded awesome!" } \\
\text { Incorrect: (e.g. Client fails to respond; Client asks for help; Client engages maladaptive behavior or } \\
\text { requires additional prompting beyond initial model). If incorrect, model as outlined above, reiterate Sd and give full vocal } \\
\text { prompting for all steps, have the client repeat. Mark as incorrect. }\end{array}$ \\
\hline \multicolumn{2}{|c|}{ Flexible Perspective Taking (Self as Context) } \\
\hline Antecedent & $\begin{array}{l}\text { Present vocal Sd: "what are some aspects of your "self'?" (once the client responds) "do you notice } \\
\text { different ways you think/feel/behave with parents vs siblings vs school vs with friends vs right now" }\end{array}$ \\
\hline Behavior & $\begin{array}{l}\text { Client will independently identify } 4 \text { different aspects of 'self' e.g. I am a brother/son/friend/student } \\
\text { ( } 4 \text { trials) and identify different ways in which the client behaves in each context ( } 4 \text { trials) (mark } \\
\text { as correct if client responds independently, mark prompt for any vocal prompts required) }\end{array}$ \\
\hline $\begin{array}{l}\text { Sample } \\
\text { Prompt }\end{array}$ & $\begin{array}{l}\text { "I'll try and then you can try: I am a friend and a therapist. I notice that when I am with my friends, } \\
\text { I feel I can say anything, and I talk about life a lot. I notice when I am with my clients, I stay } \\
\text { professional and try to remain caring and do a good job." }\end{array}$ \\
\hline Consequence & Correct: VR4 descriptive praise for appropriate independent responses. \\
\hline
\end{tabular}


Table 1 (continued)

\begin{tabular}{|c|c|}
\hline Goal Step & Description \\
\hline & $\begin{array}{l}\text { Incorrect: (e.g. Client fails to respond; Client asks for help; Client engages maladaptive behavior or } \\
\text { requires additional prompting beyond initial model). If any vocal prompt is required, mark as incorrect and mark level of additional } \\
\text { prompt required, e.g., partial or full vocal prompt. }\end{array}$ \\
\hline \multicolumn{2}{|r|}{ DNA-V (Discoverer) ${ }^{\mathrm{a}}$} \\
\hline Antecedent & $\begin{array}{l}\text { Review of what the "Discoverer" is + Vocal Sd " Can you tell me about a time that you discovered } \\
\text { a behavior that worked and a behavior that didn't work?" }\end{array}$ \\
\hline Behavior & $\begin{array}{l}\text { The client will independently tact behaviors they have discovered work and don't work, in the absence of maladaptive behavior and } \\
\text { additional prompts beyond therapists' model. }\end{array}$ \\
\hline $\begin{array}{l}\text { Sample } \\
\text { Prompt }\end{array}$ & $\begin{array}{l}\text { Review Discoverer (see thriving adolescent curriculum) with client }+ \text { model e.g., "The other day } \\
\text { I was in a meeting, and I cut someone off from speaking which made the person feel frustrated. } \\
\text { The next time I had something to say, I raised my hand and I discovered that that behavior had a } \\
\text { much better outcome than cutting someone off when they are speaking. Can you tell me about a time that you discovered something } \\
\text { that worked and something that didn't work?" }\end{array}$ \\
\hline Consequence & $\begin{array}{l}\text { Correct: Client is correct if they independently tact behaviors they have discovered work and don't work in the } \\
\text { absence of maladaptive behavior and additional prompts beyond therapists' } \\
\text { model. Provide descriptive praise on an FR1 schedule for each correct response. } \\
\text { Incorrect: (e.g. Client fails to respond; Client repeats therapists own self-evaluation; Client engages } \\
\text { maladaptive behavior or requires additional prompting beyond initial model.) Use L-M prompting to evoke the correct response } \\
\text { and then have them restate the correct response. Mark as } \\
\text { prompted/incorrect trial. }\end{array}$ \\
\hline
\end{tabular}

DNA-V (Noticer)

Antecedent Review of what the "Noticer" is + Vocal instruction "What is something you can notice in this moment?"

Behavior The client will independently tact things they notice in the moment, in the absence of maladaptive behavior and additional prompts beyond therapists' model.

Sample Model correct responses. Be sure to discuss not only things in the room (sights, sounds, etc.) but

Prompt also internal things (emotions, thoughts, etc.) Therapist may also add to visual stimuli, e.g. mess up hair, look bored, pretend to be sleeping, etc.

Consequence Correct: Client is correct if they independently tact things they have in the moment in the absence of maladaptive behavior and additional prompts beyond therapists' model. Provide descriptive praise on an FR1 schedule for each correct response.

Incorrect: (e.g. Client fails to respond; Client repeats therapists own self-evaluation; Client engages maladaptive behavior or requires additional prompting beyond initial model.) Use L-M prompting to evoke the correct response and then have the client restate the correct response. Mark as prompted/incorrect trial.

DNA-V (Advisor)

Antecedent Review of what the "Advisor" is (can be positive and negative) + Vocal Sd "can you tell me about a time that your advisor has given you advice?"

Behavior The client will independently tell you about a time that their advisor gave them advice in the absence of maladaptive behavior and additional prompts beyond therapists' model.

Sample Review of advisor (good and bad) + Model e.g. "I had a project due to my boss yesterday, that

Prompt I totally forgot about, and it was due in 3 hours. There was no way I was going to finish on time. My advisor told me "you are never going to get this done" and my advisor was right, so I needed to do something about it. I sent an email and let my boss know that I would be late turning in

the project" + "can you tell me about a time that your advisor has given you advice?

Consequence Correct: Client is correct if they independently tell you about a time that their advisor gave them advice in the absence of maladaptive behavior and additional prompts beyond therapists' model. Provide descriptive praise on an FR1 schedule for each correct response.

Incorrect: (e.g. Client fails to respond; Client repeats therapists own self-evaluation; Client engages maladaptive behavior or requires additional prompting beyond initial model.) Use L-M prompting to evoke the correct response and then have the client restate the correct response. Mark as prompted/incorrect trial.

${ }^{a}$ The concepts of Discoverer, Noticer and Advisor are taken from Hayes and Ciarrochi's (2015) Thriving Adolescent Curriculum (https://www. thrivingadolescent.com). The following examples merely outline potential ways of programming for such concepts in a format congruent with $\mathrm{ABA}$ programming and are not meant to reflect curriculum recommendations or requirements. 


\section{Conclusion}

Using ACTr in ABA may help to determine the function of socially significant, observable, and measurable overt problem behaviors, and engage the learner with flexible alternative behaviors (overt or covert) that lead to adaptive behavior change. The importance of the adequate identification of behavioral functions within ABA cannot be understated. With adequate identification, behavior analysts are more likely to design treatment goals that address the client's behavior in a precise, effective, and efficient way (Hanley, 2012). Given the complexities of analyzing behaviors that come under the control of covert verbal behavior, much more research is needed in order to determine the most effective use of functional assessment procedures to identify covert verbal behavior as variables that maintain problem behavior. Furthermore, it will be necessary to identify ways in which behavior analysts might experimentally manipulate such variables in the form of a verbal functional analysis. Although verbal functional analyses are conducted in ACT (Y. Barnes-Holmes et al., 2018), if the field of ABA is to adopt $\mathrm{ACTr}$, it will be important to continue discussing how functional analyses within $\mathrm{ACTr}$ can be conducted by behavior analysts in a way that coheres with established ABA practices (e.g. see Sandoz et al., 2021). Recent advances in RFT, including the hyperdimensional multilevel framework (D. Barnes-Holmes et al., 2020) and relating, orienting, evoking, and motivating (Harte \& Barnes-Holmes, in press), may provide interesting additional insights.

Behavior analysts and those in the field of ABA have been rightfully concerned that the implementation of ACTr may be outside of their scope of practice; however, as presented previously, ACTr may offer a way for ABA to move forward and more effectively address complex behavioral issues commonly facing individuals working in the field of ABA. That said, the relevant publications on RFT and ACTr are not sufficient to ensure a corresponding change in coursework and applied practice. If the profession is to reach a universal acceptance of the use of RFT and ACTr in ABA, the Behavior Analyst Certification Board would need to include these, or at the very least, behavior-analytic tactics to work with covert verbal behavior in the next Task List, and the Association for Behavior Analysis International would need to build similar content into the verified course sequence. This would ensure that both behavior-analytic coursework and practical fieldwork addressed content relevant to RFT and ACTr. To improve the likelihood of any eventual buy-in from the Behavior Analyst Certification Board and the Association for Behavior Analysis International, ACTr researchers will need to ensure they publish high-quality conceptual and empirical articles (see Cihon et al., 2021, for a critical review).

Author Note Sincere thanks go to Mandy Rades, BCBA, for her contribution to Table 1 .

\section{References}

Barnes-Holmes, Y., Barnes-Holmes, D., \& McHugh, L. (2004). Teaching derived relational responding to young children. Journal of Early and Intensive Behavior Intervention, 1(1), 3-12. https://doi.org/10. 1037/h0100275.

Barnes-Holmes, D., Murphy, A., Barnes-Holmes, Y., \& Stewart, I. (2010). The implicit relational assessment procedure: Exploring the impact of private versus public contexts and the response latency criterion on pro-White and anti-Black stereotyping among White Irish individuals. The Psychological Record, 60(1), 57-79.

Barnes-Holmes, D., Barnes-Holmes, Y., Luciano, C., \& McEnteggart, C. (2017). From the IRAP and REC model to a multi-dimensional multi-level framework for analyzing the dynamics of arbitrarily applicable relational responding. Journal of Contextual Behavioral Science, 6(4), 434-445. https://doi.org/10.1016/j.jcbs.2017.08.001.

Barnes-Holmes, Y., Boorman, J., Oliver, J. E., Thompson, M., McEnteggart, C., \& Coulter, C. (2018). Using conceptual developments in RFT to direct case formulation and clinical intervention: Two case summaries. Journal of Contextual Behavioral Science, 7 , 89-96. https://doi.org/10.1016/j.jcbs.2017.11.005.

Barnes-Holmes, D., Barnes-Holmes, Y. \& McEnteggart, C. (2020). Updating RFT (More Field than Frame) and its Implications for Process-based Therapy. The Psychological Record, 70, 605-624. https://doi.org/10.1007/s40732-019-00372-3.

Barnes-Holmes, Y., Hussey, I., McEnteggart, C., Barnes-Holmes, D., \& Foody, M. (2016). Scientific ambition: the relationship between relational frame theory and middle-level terms in acceptance and commitment therapy. In R. D. Zettle, S. C. Hayes, D. BarnesHolmes, \& A. Biglan (Eds.), The Wiley handbook of contextual behavioral science (pp. 365-382). Wiley-Blackwell.

Biglan, A., \& Kass, D. J. (1977). The empirical nature of behavior therapies. Behaviorism, 5(1), 1-15.

Blackledge, J. T. (2003). An introduction to relational frame theory: Basics and applications. The Behavior Analyst Today, 3(4), 421433. https://doi.org/10.1037/h0099997.

Blackledge, J. T., \& Barnes-Holmes, D. (2009). Core processes in acceptance \& commitment therapy. In J. Blackledge, J. Ciarrochi, \& F. Deane (Eds.), Acceptance and commitment therapy: Contemporary theory, research, and practice (pp. 41-58). Australian Academic Press.

Cihon, J. H., Ferguson, J. L., Leaf, J. B., Milne, C. B., Leaf, R., \& McEachin, J. (2021). Acceptance and commitment training: A review of the research. European Journal of Behavior Analysis. Advance online publication. https://doi.org/10.1080/15021149. 2021.1880688

Cooper, J. O., Heron, T. E., \& Heward, W. L. (2007). Applied behavior analysis (2nd ed.). Pearson.

Coyne, L. W., Gould, E. R., Grimaldi, M., Wilson, K. G., Baffuto, G., \& Biglan, A. (2020). First things first: Parent psychological flexibility and self-compassion during COVID-19. Behavior Analysis in Practice, 1-7. Advance online publication. https://doi.org/10.1007/ s40617-020-00435-w.

de Carvalho, M. P., \& de Rose, J. C. (2014). Understanding racial attitudes through the stimulus equivalence paradigm. The Psychological Record, 64, 527-536.

Dixon, M. R., \& Paliliunas, D. (2018). AIM: A behavior analytic curriculum for social-emotional development in children. Shawnee Scientific Press.

Dixon, M. R., Hayes, S. C., Stanley, C., Law, S., \& al-Nasser, T. (2020). Is acceptance and commitment training or therapy (ACT) a method that applied behavior analysts can and should use? The Psychological Record 70(4):559-579 
Dymond, S., \& Rehfeldt, R. A. (2000). Understanding complex behavior: The transformation of stimulus functions. The Behavior Analyst, 23(2), 239-254. https://doi.org/10.1007/BF03392013.

Enoch, M. R., \& Nicholson, S. L. (2020). Acceptance and commitment therapy and relational frame theory in the field of applied behavior analysis: The acceptability and perspective of the practicing BCBA. Behavior Analysis in Practice 13(3), 609-617. https://doi.org/10. 1007/s40617-020-00416-Z.

Foody, M., Barnes-Holmes, Y., Barnes-Holmes, D., \& Luciano, C. (2013). An empirical investigation of hierarchical versus distinction relations in a self-based ACT exercise. International Journal of Psychology and Psychological Therapy, 13, 373-385.

Friman, P. C., Hayes, S. C., \& Wilson, K. G. (1998). Why behavior analysts should study emotion: The example of anxiety. Journal of Applied Behavior Analysis, 31, 137-156.

Fryling, M., Rehfeldt, R. A., Tarbox, J., \& Hayes, L. J. (2020). Applied behavior analysis of language and cognition. Context Press/New Harbinger

Gould, E. R., Tarbox, J., \& Coyne, L. (2018). Evaluating the effects of acceptance and commitment training on the overt behavior of parents of children with autism. Journal of Contextual Behavioral Science, 7, 81-88.

Guinther, P. M., \& Dougher, M. J. (2015). The clinical relevance of stimulus equivalence and relational frame theory in influencing the behavior of verbally competent adults. Current Opinion in Psychology, 2, 21-25. https://doi.org/10.1016/j.copsyc.2015.01. 015 .

Hanley, G. (2012). Functional assessment of problem behavior: Dispelling myths, overcoming implementation obstacles, and developing new lore. Behavior Analysis in Practice, 5, 54-72. https://doi. org/10.1007/BF03391818.

Harte, C., \& Barnes-Holmes, D. (in press). A primer on relational frame theory (RFT). In M. P. Twohig, M. E. Levin, \& J. M. Peterson (Eds.), The Oxford handbook of acceptance and commitment therapy. Oxford University Press.

Hayes, L. L., \& Ciarrochi, J. (2015). The thriving adolescent: Using acceptance and commitment therapy and positive psychology to help teens manage emotions, achieve goals, and build connection. New Harbinger Publications.

Hayes, S.C., Bissett, R., Roget, N., Padilla, M., Kohlenberg, B. S., Fisher, G., Masuda, A., Pistorello, J., Rye, A. K., Berry, K., \& Niccolls, R. (2004a). The impact of acceptance and commitment training and multicultural training on the stigmatizing attitudes and professional burnout of substance abuse counselors. Behavior Therapy 35(4): $821-835$.

Hayes S.C., Strosahl K.D., Bunting K., Twohig M., Wilson K.G. (2004b) What Is Acceptance and Commitment Therapy? In: Hayes S.C., Strosahl K.D. (eds) A practical guide to acceptance and commitment therapy. Springer https://doi.org/10.1007/978-0-387-2336971

Hayes, S. C., Strosahl, K. D., \& Wilson, K. G. (1999). Acceptance and commitment therapy: An experiential approach to behavior change. Guilford Press.

Hughes, S., \& Barnes-Holmes, D. (2016). Relational frame theory: Implications for the study of human language and cognition. In R. D. Zettle, S. C. Hayes, D. Barnes-Holmes, \& A. Biglan (Eds.), The Wiley handbook of contextual behavioral science (pp. 179-226). Wiley Blackwell.

Hayes, S. C., Barnes-Holmes, D., \& Roche, B. (Eds.). (2001). Relational frame theory: A post-Skinnerian account of human language and cognition. Plenum Press.

Hayes, S. C., Luoma, J. B., Bond, F. W., Masuda, A., \& Lillis, J. (2006). Acceptance and commitment therapy: Model, processes and outcomes. Behavior Research \& Therapy, 44, 1-25.

Iwata, B. A., Dorsey, M. F., Slifer, K. J., Bauman, K. E., \& Richman, G. S. (1994). Toward a functional analysis of self-injury. Journal of
Applied Behavior Analysis, 27(2), 197-209. https://doi.org/10.1901/ jaba.1994.27-197.

Hoffmann, A. N., Contreras, B. P., Clay, C. J., \& Twohig, M. P. (2016). Acceptance and commitment therapy for individuals with disabilities: A behavior analytic strategy for addressing private events in challenging behavior. Behavior Analysis in Practice, 9, 14-24.

Harrison, A. (Host). (2020). Listening to Perspectives That Matter: Session 120 [Audio podcast episode]. In The Behavioral Observations Podcast with Matt Cicoria. Podcast Addict. https:// behavioralobservations.com/listening-to-perspectives-that-mattersession-120/

Kazdin, A. E. (1982). Single-case research design. Oxford University Press.

Kelly, M. E. (2020). The potential of a relational training intervention to improve older adults' cognition. Behavior Analysis in Practice, 13(3), 684-697. https://doi.org/10.1007/s40617-02000415-0.

Little, A., Tarbox, J., \& Alzaabi, K. (2020). Using acceptance and commitment training to enhance the effectiveness of behavioral skills training. Journal of Contextual Behavioral Science, 16, 9-16.

Matsuda, K., Garcia, Y., Catagnus, R., \& Ackerlund Brandt, J. (2020). Can behavior analysis help us understand and reduce racism? A review of the current literature. Behavior Analysis in Practice, 13, 336-347. https://doi.org/10.1007/s40617-020-00411-4.

McHugh, L., Barnes-Holmes, Y., \& Barnes-Holmes, D. (2004). Perspective-taking as relational responding: A developmental profile. Psychological Record, 54, 115-144.

McKeel, A. N., Rowsey, K. E., Belisle, J., Dixon, M. R., \& Szekely, S. (2015). Teaching complex verbal operants with the PEAK Relational Training System. Behavior Analysis in Practice, 8(2), 241-244. https://doi.org/10.1007/s40617-015-0067-y.

Moran, D. J. (2011). ACT for leadership: Using acceptance and commitment training to develop crisis-resilient change managers. International Journal of Behavioral Consultation and Therapy, 7(1), 66-75. https://doi.org/10.1037/h0100928.

Murphy, C., Barnes-Holmes, D., \& Barnes-Holmes, Y. (2005). Derived manding in children with autism: Synthesizing Skinner's verbal behavior with relational frame theory. Journal of Applied Behavior Analysis, 38(4), 445-462. https://doi.org/10.1901/jaba.2005.97-04.

Pennie, B., \& Barnes-Holmes, Y. (2019). A Complete Guide to the Science of Self-Talk: How to stop rumination, compulsive thinking, unrealistic rule-following, and negative self-talk. Better Humans. https://betterhumans.pub/a-complete-guide-to-the-science-of-selftalk-9da0c478fe62.

Pennie, B., \& Kelly, M. E. (2018). An examination of generalised implicit biases towards "wanting more" as a proxy measure of materialistic behaviour: A relational frame theory (RFT) perspective. Journal of Contextual Behavioral Science, 8, 17-28. https://doi.org/10.1016/j. jcbs.2018.02.004.

Rehfeldt, R. A., \& Barnes-Holmes, Y. (2009). Derived relational responding: Applications for learners with autism and other developmental disabilities. New Harbinger Publications, Inc.

Rehfeldt, R. A., Dillen, J. E., Ziomek, M. M., \& Kowalchuk, R. K. (2007). Assessing relational learning deficits in perspective-taking in children with high-functioning autism spectrum disorder. The Psychological Record, 57(1), 23-47.

Sandoz, E. K., Gould, E. R. \& DuFrene, T. (2021). Ongoing, explicit, and direct functional assessment is a necessary component of ACT as behavior analysis: A response to Tarbox et al. (2020). Behavior Analysis in Practice. Advance online publication. https://doi.org/ 10.1007/s40617-021-00607-2.

Skinner, B. F. (1945). The operational analysis of psychological terms Psychological Review, 52(5), 270-277.

Skinner, B. F. (1969). Contingencies of reinforcement. AppletonCentury-Crofts. 
Szabo, T. G., \& Tarbox, J. (2015). Beyond what "is" and "is not". Journal of Contextual Behavioral Science, 4, 220-224.

Szabo, T. G., Richling, S., Embry, D. D., Biglan, A., \& Wilson, K. (2020). From helpless to hero: Promoting values-based behavior and positive family interaction in the midst of COVID-19. Behavior Analysis in Practice, 13(3), 568-576. https://doi.org/10. 1007/s40617-020-00431-0.

Tarbox, C. M., Silverman, E. A., Chastain, A. N., Little, A., Bermudez, T. L., \& Tarbox, J. (2020a). Taking ACTion: 18 simple strategies for supporting children with autism during the COVID-19 pandemic. Behavior Analysis in Practice, 1-29. Advance online publication. https://doi.org/10.1007/s40617-020-00448-5
Tarbox, J., Szabo, T., \& Aclan, M. (2020b). Acceptance and commitment training within the scope of practice of applied behavior analysis. Behavior Analysis in Practice, 1-22. Advance online publication. https://doi.org/10.1007/s40617-020-00466-3.

Zettle, R. D. (2005). The evolution of a contextual approach to therapy: From comprehensive distancing to ACT. International Journal of Behavioral and Consultation Therapy, 1, 77-89.

Publisher's Note Springer Nature remains neutral with regard to jurisdictional claims in published maps and institutional affiliations. 